\title{
LOBATTO TYPE QUADRATURE RULES FOR FUNCTIONS WITH BOUNDED DERIVATIVE
}

\author{
P. CERone And S. S. Dragomir
}

\begin{abstract}
Inequalities are obtained for quadrature rules in terms of upper and lower bounds of the first derivative of the integrand. Bounds of Ostrowski type quadrature rules are obtained and the classical Iyengar inequality for the trapezoidal rule is recaptured as a special case. Applications to numerical integration are demonstrated.
\end{abstract}

Mathematics subject classification (1991): 26D15, 26D99 41A55.

Key words and phrases: Hayashi, Iyengar and Ostrowski inequalities, Quadrature formulae.

\section{REFERENCES}

[1] R.P. Agarwal and S.S. Dragomir, An application of Hayashi's inequality for differentiable functions, Computers Math. Appl., 32(6) (1996), 95-99.

[2] D.S. Mitrinović, J.E. Pećarić and A.M. Fink, Classical and New Inequalities in Analysis, Kluwer Academic Publishers, 1993.

[3] D.S Mitrinović, J.E. Pećarić and A.M. Fink, Inequalities for Functions and Their Integrals and Derivatives, Kluwer Academic Publishers, 1994.

[4] S.S. Dragomir and S. Wang, Applications of Iyengar's type inequalities to the estimation of error bounds for the trapezoidal quadrature rule, Tamkang Journal of Mathematics, 29(1) (1998), 55-58.

[5] S.S. Dragomir, Y.J. Cho and S.S. Kim, Some remarks on the Milovanović-Pečarić Inequality and in Applications for special means and numerical integration, Tamkang Journal of Mathematics. 30(3) (1999), 203-211. 